\title{
Comparative study on different incorporation of olive oil and dill extract in fresh cheese
}

\author{
*Ivanova, M., Balabanova, T., Kostov, G. and Uzunova, G. \\ Technological Faculty, University of Food Technologies, 26 Maritsa blvd., 4002 Plovdiv, Bulgaria
}

\author{
Article history: \\ Received: 10 July 2020 \\ Received in revised form: 21 \\ July 2020 \\ Accepted: 16 August 2020 \\ Available Online: 26 \\ September 2020
}

\section{Keywords:}

Antioxidant,

Dill extract,

Encapsulation,

Fresh cheese,

Olive oil,

Unsaturated fatty acids

DOI:

https://doi.org/10.26656/fr.2017.4(6).341

\begin{abstract}
In the present study, a comparative analysis was undertaken on the possibilities of using olive oil in fresh spreadable cheese either emulsified or encapsulated. The changes in titratable acidity, active acidity and total Lactococcus count were recorded continuously throughout the storage period. At the end of the storage period, Lactococcus count in the samples with encapsulated oil were found to be slightly higher (7.7 and $7.8 \log$ CFU.g ${ }^{-1}$ respectively) in comparison with the control sample (7.5 log CFU.g $\left.{ }^{-1}\right)$. A significantly higher content $(\mathrm{P}<0.05)$ of unsaturated fatty acids $(56.88 \mathrm{~g}$ per $100 \mathrm{~g}$ fatty acids) and a lower peroxide value of extracted fat $\left(0.35 \mathrm{meqO} \mathrm{O}_{2} \cdot \mathrm{kg}^{-1}\right)$ were found in the fresh spreadable cheese samples with $4 \%(\mathrm{w} / \mathrm{w})$ encapsulated olive oil and extract of dill used as antioxidant in an amount of $0.003 \%(\mathrm{v} / \mathrm{v})$. The addition of antioxidant (dill extract) further reduced oxidation process and enhanced cheese functionality. The sensory profile of the fresh cheeses, containing encapsulated oil, was better compared to the sensory profile of the products prepared with directly added olive oil (with or without added antioxidant).
\end{abstract}

\section{Introduction}

Vegetable oils are characterized by high levels of unsaturated fatty acids and presence of natural antioxidants - carotenes, vitamin E etc. Several studies (Abdelhamid et al., 2018; Ramji, 2019) have recognized the beneficial effect of mono and polyunsaturated fatty acids in the prevention of various diseases. Monounsaturated oleic acid in the olive oil represents 50 $-83 \%(\mathrm{w} / \mathrm{w})$ of its unsaturated fatty acids. The amount of polyunsaturated fatty acids is in the range of $7-16 \%(\mathrm{w} /$ $\mathrm{w}$ ), and the proportion of saturated fatty acids is between 11 and $20 \%(\mathrm{w} / \mathrm{w})$. The favorable ratio of unsaturated to saturated fatty acids enhances the nutritional and biological value of olive oil (Liu et al., 2017).

Many clinical trials have been carried out that demonstrated the benefits of replacing milk fat with vegetable oils rich in unsaturated fatty acids (Dawczynski et al., 2010; Siri-Tarino et al., 2015). The creation of dairy products fortified with mono and polyunsaturated fatty acids is a promising perspective but also a challenge to science as regards the prevention of lipid oxidation in the storage period (Lanier and Corl, 2015). Therefore, the fortification of dairy products with unsaturated fatty acids requires the addition of antioxidants.
Antioxidants are naturally occurring or synthetic substances, which, when included in dairy products with partial substitution of milk fat by vegetable oil, inhibit auto-oxidation processes. Natural antioxidants are tocopherols, lecithin, carotenoids, herb and spice extracts (Xu et al., 2017). Dill extract is suitable for use in dairy products, because of the good sensory combination of the two products. In addition, it is characterized by excellent antioxidant properties due to the high phenolic compounds content (Isbilir and Sagiroglu, 2011).

It has been established that auto-oxidation will manifest itself during the storage period of the product, though at a slow rate, regardless of the fact that an antioxidant is included in a food product (Domínguez et al., 2019). An appropriate approach against autooxidation is microencapsulation of vegetable oils. The main objective of this technology is to boost the encapsulated oil stability during storage. Thus, the dispersity of fat-soluble ingredients and hygiene during storage will be improved, unsaturated fatty acids will be more effectively assimilated in the intestinal tract of humans, and while on the other hand, the negative effect on the flavor and texture profile of the finished product will be precluded (Ruiz et al., 2017; Chang and Nickerson, 2018). 
The purpose of this study was to conduct a comparative analysis on the possibilities to include olive oil, either emulsified or encapsulated, in fresh cheese manufacture, as well as a natural antioxidant (extract of dill).

\section{Materials and methods}

\subsection{Material}

Whole cow milk (3.6\% fat content) and cream (38\% fat content) were purchased from a dairy factory in Plovdiv, Bulgaria. Olive oil was purchased from a retail market in Plovdiv, Bulgaria with 98\% fat content.

A freeze-dried starter culture was used, intended for production of fresh cheese by Lactina LTD, Bankya, Bulgaria, with the following composition: Lactococcus lactis subsp. lactis, Lactococcus lactis subsp. cremoris, more than $9.5 \times 10^{9} \cdot \mathrm{g}^{-1}$ in an amount of $3 \%(\mathrm{v} / \mathrm{v})$. Rennet - Daniren ${ }^{\circledR}$ pure chymosin by Biokom Trendafilov, Sliven, Bulgaria, with a milk-clotting activity of 1:15000, pH 5.4-5.6.

For the preparation of the alginate beads was used medium viscosity sodium alginate, available from Sigma -Aldrich, Sofia, Bulgaria. $7 \mathrm{~g}$ of alginate beads contained $4 \%$ fat content.

The antioxidant used was dill extract in an amount of $0.003 \%(\mathrm{v} / \mathrm{v})$ with known characteristics, dill extract by Ekstraktum LTD, Plovdiv, Bulgaria whose main components of the chemical composition were: Dcarvone $53.12 \% \quad(\mathrm{w} / \mathrm{w})$, limonene $37.12 \% \quad(\mathrm{w} / \mathrm{w})$, dihydrocarvone $2.58 \%(\mathrm{w} / \mathrm{w})$, p-cymene $0.35 \%(\mathrm{w} / \mathrm{w}), \gamma$ terpinene $0.45 \%(\mathrm{w} / \mathrm{w})$, etc. and high antioxidant activity (Nenov et al., 2013).

The emulsifier used was glycerol monostearate in an amount of $0.1 \%$ (w/v) according to Eustone (2008).

\subsection{Fresh cheese manufacture}

For the purposes of the experiment, the following cheese variants were made:

- F (control) and FA (control with antioxidant) - the antioxidant was added during the process of milk normalization.

- E and EA - the olive oil alone and olive oil plus antioxidant for direct incorporation into milk for cheese making were in the form of emulsion (2.2.1.) and were added prior to pasteurization.

- C and CA - olive oil beads (2.2.2.) and olive oil beads plus antioxidant were added to milk before the process of milk curdling.
The amount of cream, olive oil and encapsulated olive oil to be added was calculated according to Pearson's rule for milk fat standardization in order to reach $8 \%$ fat content in the final product (Table 1).

Table 1. List of experimental variants

\begin{tabular}{ccccc}
\hline Sample & $\begin{array}{c}\text { Fat content } \\
\text { of product, } \\
\%(\mathrm{w} / \mathrm{w})\end{array}$ & $\begin{array}{c}\text { Amount of } \\
\text { olive oil, } \\
\%(\mathrm{w} / \mathrm{w})\end{array}$ & $\begin{array}{c}\text { Amount of } \\
\text { milk fat, } \\
\%(\mathrm{w} / \mathrm{w})\end{array}$ & $\begin{array}{c}\text { Amount of } \\
\text { antioxidant, } \\
\%(\mathrm{v} / \mathrm{v})\end{array}$ \\
\hline F & 8 & 0 & 8 & 0 \\
FA & 8 & 0 & 8 & 0.003 \\
E & 8 & 4 & 4 & 0 \\
EA & 8 & 4 & 4 & 0.003 \\
C & 8 & 4 & 4 & 0 \\
CA & 8 & 4 & 4 & 0.003 \\
\hline
\end{tabular}

F control sample (fresh cheese); FA control sample (fresh cheese) with added antioxidant (dill extract); E fresh cheese with directly added olive oil; EA fresh cheese with directly added olive oil and antioxidant (dill extract); $\mathrm{C}$ fresh cheese with encapsulated olive oil; CA fresh cheese with encapsulated olive oil and antioxidant (dill extract).

Experimental samples were obtained according to previously elaborated flowchart of the fresh spreadable cheese-making process (Ivanova, 2016) with slight modifications. Qualification of milk $\rightarrow$ Standardization of milk fat to $8 \%(\mathrm{w} / \mathrm{w})-8 \%(\mathrm{w} / \mathrm{w})$ milk fat (for batch $\mathrm{F}$ ) and $4 \%(\mathrm{w} / \mathrm{w})$ olive oil $+4 \%(\mathrm{w} / \mathrm{w})$ milk fat (for batch $\mathrm{E}$ and $\mathrm{C}$ ) with addition of antioxidant $0.003 \%(\mathrm{v} / \mathrm{v})$ (for batch FA, EA and CA) $\rightarrow$ Heat treatment of milk and addition of emulsifier $\mathrm{t}=55-60^{\circ} \mathrm{C}$ and glyceryl monostearate $(0.1 \%(\mathrm{w} / \mathrm{v}) \rightarrow$ Obtaining of emulsion $\rightarrow$ Pasteurization $\left(88^{\circ} \mathrm{C}\right.$, duration $\left.5 \mathrm{~min}\right) \rightarrow$ Cooling $\left(25^{\circ} \mathrm{C}\right)$ $\rightarrow$ Inoculation $(3 \% \quad(\mathrm{v} / \mathrm{v})$ starter culture) $\rightarrow$ Prebiological ripening (an increase in titratable acidity of $0.018-0.027$ represented as \% lactic acid) $\rightarrow$ Addition of rennet $(0.005 \%(\mathrm{v} / \mathrm{v})) \rightarrow$ Coagulation $(14-16 \mathrm{~h}) \rightarrow$ Cutting of the gel and curd retention in the whey for 30 min at a temperature of $20-25^{\circ} \mathrm{C} \rightarrow$ Drainage and selfpressing to dry matter $30 \%(\mathrm{w} / \mathrm{w}) \rightarrow$ At a temperature of $20-22^{\circ} \mathrm{C}$ for $1-2 \mathrm{~h} \rightarrow$ At a temperature of $4-6^{\circ} \mathrm{C}$ overnight $\rightarrow$ Dry salting $\mathrm{NaCl} \quad(0.5 \%(\mathrm{w} / \mathrm{v})) \rightarrow$ Homogenization of the curd $\rightarrow$ Packaging and storage. The experiment was conducted in the Laboratory of "Milk and Dairy Products", UFT, Plovdiv, Bulgaria.

\subsubsection{Emulsion preparation}

Oil in water emulsion (batch E) was prepared with emulsifier glycerol monostearate in an amount of $0.1 \%$ (w/v), and olive oil according to the Pearson's rule calculation. The emulsion preparation was carried out by mixing the oil phase with the dispersion medium under constant stirring (15 $000 \mathrm{rpm}$ ) for $5 \mathrm{~min}$ on a laboratory IKA®T-18 Ultra Turrax Digital, Staufen, Germany, homogenizer, and at a temperature of $55-60^{\circ} \mathrm{C}$, to obtain 
a complete dissolution of the emulsifier (Vlaseva, 2014). The experiment was conducted in the Laboratory of "Milk and Dairy Products", UFT, Plovdiv, Bulgaria.

\subsubsection{Alginate beads preparation}

For the purposes of the experiment (batch F), a solution with a concentration of $1.37 \%(\mathrm{w} / \mathrm{v})$ was prepared (Poirieux et al., 2017). The alginate was soaked in the appropriate quantity of distilled water for $24 \mathrm{hrs}$ until completely dissolved, then sterilized in a microwave oven ( $800 \mathrm{~W}$ for 5 mins) to ensure microbiological stability of the solution. Olive oil in a concentration of $30 \%(\mathrm{v} / \mathrm{v})$ was added to the already finished alginate solution and the emulsion was homogenized at $17150 \mathrm{rpm}$. The homogenized emulsion was dropped into a $2 \%(\mathrm{w} / \mathrm{v}) \mathrm{CaCl}_{2}$ solution using a peristaltic pump. Afterwards, the gel beads remained for further $30 \mathrm{mins}$ in the gelling solution until the required mechanical stability was achieved. The resulting capsules were washed with distilled water and left for 12 -24 hrs to dry under refrigeration conditions, and were then added to the product. The conditions for the formation of the alginate-olive oil emulsion have been optimized, and the principle of optimization is presented in Poirieux et al. (2017). The experiment was conducted in the Laboratory of "Technology of Wine and Beer", UFT, Plovdiv, Bulgaria.

\subsection{Chemical analyses}

Chemical analyses were performed in the Laboratories of "Milk and Dairy Products", "Technology of Wine and Beer" and "Technology of Essential Oils" UFT, Plovdiv, Bulgaria.

\subsubsection{Titratable acidity of cheese}

The acidity of the samples was determined by Thorner's method (Bulgarian National Standard BNS 1111-80), and presented as a percentage of lactic acid.

\subsubsection{Active acidity of cheese}

The $\mathrm{pH}$ of the samples was determined by potentiometric methods, using the WTW $7110 \mathrm{pH}$ meter, Weilheim, Germany.

\subsubsection{Peroxide value of extracted fat}

Fat extraction for determination of the peroxide value was carried out by the method of Bligh and Deyer (1959). The iodometric method was used, based on the interaction of active peroxide or hydro peroxide with iodide in the presence of acetic acid (ISO EN 3960:2008).

\subsubsection{Fatty acid composition of extracted fat}

The fatty acid composition of the samples was determined after fat extraction by the method of Schmidt -Bonzynsky-Ratzaloff (ISO 1735|IDF 5:2004). The preparation of methyl esters of the fatty acids was in compliance with ISO 5509:2000. The analysis of methyl esters of fatty acids was carried out by gas chromatographic method (ISO 5508:2004).

\subsection{Microbiological analyses}

Microbiological analyses were performed in the Laboratory of "Milk and Dairy Products", UFT, Plovdiv, Bulgaria.

Total Lactococcus count - sample preparation in accordance with ISO 6887-5:2020. Suitable dilutions were subsequently inoculated on selective culture medium M17, according to ISO 17792:2006.

\subsection{Sensory analysis}

The sensory evaluation of the fresh cheeses was conducted in accordance with the Bulgarian National Standard BNS 15612-83, and ISO $6654-83$ by 15 experienced panelists in the Laboratory of "Milk and Dairy Products", UFT, Plovdiv, Bulgaria. The evaluation criteria were the following: flavor - 35 points, texture 25 points, structure -20 points, appearance -10 points, and color - 10 points (maximum overall score - 100 points). The results were equated to a 10-point evaluation scale for the purpose of being presented in a spider diagram.

\subsection{Statistical analyses}

Computer processing of results was performed using Microsoft Excel 2010 (ANOVA). Multiple comparisons were made with the LSD procedure. Results are presented as the mean $\pm \mathrm{SD}$ (standard deviation) $(n=4)$.

\section{Results and discussion}

\subsection{Chemical analysis}

The results about the parameter changes - $\mathrm{pH}$ and lactic acid amount of the experimental samples of fresh cheeses were determined continuously during storage at $4^{\circ} \mathrm{C}$ for seven days (Figure $1 \mathrm{~A}$ and $\mathrm{B}$ ).

Our results confirmed that lactose fermentation initiated by the enzymatic systems of the starter lactic acid bacteria cause the formation of lactic acid and other organic acids in cheese, as confirmed by Aini et al. (2020). On the first day of storage the amount of lactic acid formed was significantly higher $(\mathrm{P}<0.05)$ in the control sample $\mathrm{F}$, while the levels in the other variants were in the range between $0.80-1.00 \%$ lactic acid. In the 
samples containing an antioxidant and olive oil the amount of lactic acid was the lowest, therefore, the values reported for the $\mathrm{pH}$ parameter were higher. The trend in these results was explained by Kyeong et al. (2017). This was due to the more moderate lactic acid fermentation in the presence of the added antioxidant (extract of dill), and the natural antioxidants present in

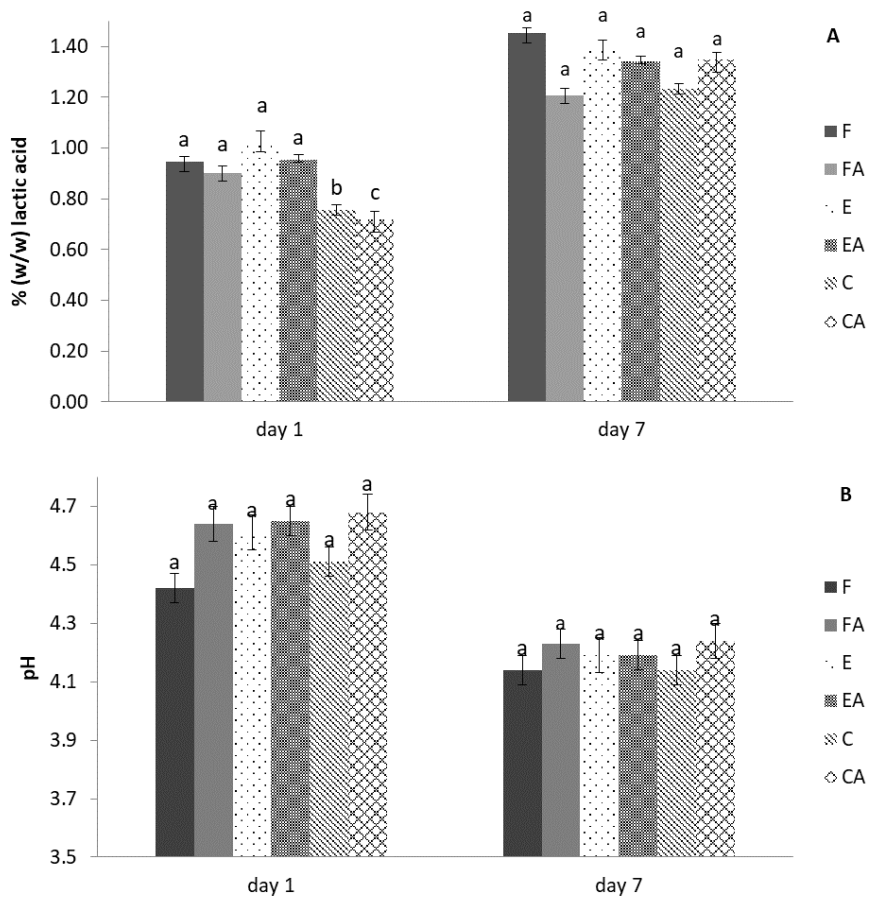

Figure 1. Changes in acidity (A) and pH (B) of different fresh cheese samples during 7 days of storage. $F$ control sample (fresh cheese); FA control sample (fresh cheese) with added antioxidant (dill extract); $\mathrm{E}$ fresh cheese with directly added olive oil; EA fresh cheese with directly added olive oil and antioxidant (dill extract); $\mathrm{C}$ fresh cheese with encapsulated olive oil; CA fresh cheese with encapsulated olive oil and antioxidant (dill extract); Different letters in the same row show statistically significant differences $(\mathrm{P}<0.05)$ during storage.

olive oil.

During storage, there was a continuous tendency towards an increase in the amount of lactic acid $-1.2 \%$ $(\mathrm{v} / \mathrm{v})$, and a decrease in the $\mathrm{pH}$ values of the experimental cheese samples. At the end of the storage period, samples $\mathrm{F}$ and $\mathrm{E}$ were characterized by higher acid-forming capacity, while variants FA, EA, C and CA showed a more moderate rate of lactic acid formation. The active acidity of these cheese samples was between 4.1 and 4.23 , respectively. The values of $\mathrm{pH}$ in sample $\mathrm{E}$ can be explained with the likely onset of primary oxidation processes in olive oil. Our results were comparable with the reported studies of Felfoul et al. (2016).

The nutritional and biological value of fats in foods is determined by the amount and ratio of saturated to unsaturated fatty acids and by the ratio between nonessential and essential fatty acids (Table 2).

The results revealed that the level of short-chain saturated fatty acids - caproic, caprylic and capric, is the highest in samples FA and F, followed by variants $\mathrm{C}$ and $\mathrm{CA}$, and it was the lowest in samples $\mathrm{E}$ and EA. At the end of the storage, the palmitic, lauric and stearic fatty acids accounted for the largest share of total saturated fatty acids in all experimental samples. The content of palmitic acid was higher in samples $F$ and FA than in variants $\mathrm{E}, \mathrm{EA}, \mathrm{C}$ and $\mathrm{CA}$, while the lauric acid content was lower in E, EA, C and CA as compared to samples F and FA. Al-Ismail et al. (2015) observed the same tendency in processed cheese analogue with selected vegetable oils.

Of the unsaturated fatty acids, the content of oleic acid was the highest, and approximately twice higher in comparison with samples C and CA (about 50\% (w/w) of extracted fat) compared to variants $\mathrm{F}$ and FA (about $25 \%(\mathrm{w} / \mathrm{w})$ of extracted fat). The total content of unsaturated fatty acids in samples $\mathrm{E}$ and $\mathrm{C}$ exceed $52.0 \%$ $(\mathrm{w} / \mathrm{w})$, for variants EA and CA it reaches a value of about $50.0 \%(\mathrm{w} / \mathrm{w})$, and in the control cheese samples with and without antioxidant - 30\% (w/w) of the extracted fat. These results indicated that the experimental fresh cheese samples fortified with olive oil were characterized by a higher content of unsaturated fatty acids as compared to the control sample. Similar results were reported by Dal Bello et al. (2017) who investigated the possibilities to use fresh cheese as a vehicle for polyunsaturated fatty acids integration. The experimental samples of fresh cheese with added olive oil were characterized by a higher content of essential fatty acids. Bakry et al. (2016) summarized the effect of microencapsulation of vegetable oil on chemical and physical reactions in foods. Their study confirmed our results which showed that the highest proportion of unsaturated fatty acids was established in the samples containing microencapsulated olive oil in comparison with the control and the samples with emulsified vegetable oil. Kaptan and Sivri (2018) reported that adding medicinal and aromatic plant extracts, as dill extract, increased the beneficial effect of polyunsaturated fatty acids and represented an additional source of bioactive compounds as natural antioxidants.

The determination of the peroxide value of the fat is a measure of the degree of oxidation present in the experimental samples. Fat oxidation processes deteriorate the sensory characteristics and curtail the shelf life of products (Amit et al., 2017).

The results showed that there was a statistically significant difference $(\mathrm{P}<0.05)$ between the peroxide 
Table 2. Fatty acid profile (g per 100g fatty acids) of different fresh cheese samples after 7 days of storage

\begin{tabular}{|c|c|c|c|c|c|c|}
\hline Fatty acid & $\mathrm{F}$ & FA & $\mathrm{E}$ & EA & $\mathrm{C}$ & $\mathrm{CA}$ \\
\hline \multicolumn{7}{|l|}{ Saturated fatty acids } \\
\hline Butyric $\mathrm{C}_{4: 0}$ & $0.14 \pm 0.08^{\mathrm{a}}$ & $0.24 \pm 0.08^{\mathrm{a}}$ & $\mathrm{ND} * *$ & $0.19 \pm 0.09^{\mathrm{a}}$ & $0.24 \pm 0.04^{\mathrm{a}}$ & $0.32 \pm 0.10^{\mathrm{a}}$ \\
\hline Caproic $\mathrm{C}_{6: 0}$ & $0.58 \pm 0.22^{\mathrm{a}}$ & $0.91 \pm 0.15^{\mathrm{a}}$ & $0.88 \pm 0.10^{\mathrm{a}}$ & $1.10 \pm 0.36^{\mathrm{a}}$ & $1.09 \pm 0.35^{\mathrm{a}}$ & $1.26 \pm 0.50^{\mathrm{a}}$ \\
\hline Caprylic $\mathrm{C}_{8: 0}$ & $3.06 \pm 0.20^{\mathrm{a}}$ & $3.36 \pm 0.21^{\mathrm{a}}$ & $1.63 \pm 0.05^{\mathrm{b}}$ & $1.65 \pm 0.20^{\mathrm{b}}$ & $1.65 \pm 0.19^{\mathrm{b}}$ & $2.08 \pm 0.22^{b}$ \\
\hline Capric $\mathrm{C}_{10: 0}$ & $3.20 \pm 0.30^{\mathrm{a}}$ & $3.94 \pm 0.31^{\mathrm{a}}$ & $0.06 \pm 0.01^{\mathrm{b}}$ & $0.10 \pm 0.01^{b}$ & $0.05 \pm 0.01^{\mathrm{b}}$ & $0.12 \pm 0.02^{b}$ \\
\hline Lauric $\mathrm{C}_{12: 0}$ & $11.22 \pm 0.42^{\mathrm{a}}$ & $12.33 \pm 0.69^{\mathrm{a}}$ & $5.65 \pm 0.23^{b}$ & $5.56 \pm 0.21^{\mathrm{b}}$ & $5.64 \pm 0.25^{\mathrm{b}}$ & $6.78 \pm 0.89^{b}$ \\
\hline Tridecylic $\mathrm{C}_{13: 0}$ & $1.92 \pm 0.20^{\mathrm{a}}$ & $2.24 \pm 0.20^{\mathrm{a}}$ & $0.98 \pm 0.15^{\mathrm{b}}$ & $0.89 \pm 0.16^{\mathrm{b}}$ & $0.84 \pm 0.15^{\mathrm{b}}$ & $1.08 \pm 0.10^{\mathrm{b}}$ \\
\hline Myristic $\mathrm{C}_{14: 0}$ & $1.41 \pm 0.11^{\mathrm{a}}$ & $1.54 \pm 0.11^{\mathrm{a}}$ & $0.76 \pm 0.10^{\mathrm{b}}$ & $0.68 \pm 0.11^{b}$ & $0.61 \pm 0.12^{b}$ & $0.80 \pm 0.15^{\mathrm{b}}$ \\
\hline Palmitic $\mathrm{C}_{16: 0}$ & $34.51 \pm 3.12^{\mathrm{a}}$ & $34.70 \pm 2.89^{\mathrm{a}}$ & $23.11 \pm 2.22^{b}$ & $22.21 \pm 2.11^{\mathrm{b}}$ & $22.88 \pm 2.45^{b}$ & $25.00 \pm 2.55^{\natural}$ \\
\hline Margaric $C_{17: 0}$ & $0.33 \pm 0.11^{\mathrm{a}}$ & $0.32 \pm 0.10^{\mathrm{a}}$ & $0.48 \pm 0.11^{\mathrm{a}}$ & $0.36 \pm 0.10^{\mathrm{a}}$ & $0.36 \pm 0.11^{\mathrm{a}}$ & $0.41 \pm 0.11^{\mathrm{a}}$ \\
\hline Stearic $\mathrm{C}_{18: 0}$ & $7.76 \pm 0.88^{\mathrm{a}}$ & $6.41 \pm 0.58^{\mathrm{a}}$ & $4.82 \pm 0.44^{\mathrm{b}}$ & $4.52 \pm 0.45^{\mathrm{b}}$ & $4.66 \pm 0.48^{b}$ & $5.27 \pm 0.50^{\mathrm{b}}$ \\
\hline \multicolumn{7}{|c|}{ Unsaturated fatty acids } \\
\hline Myristoleic $C_{14: 1}$ & $0.31 \pm 0.11^{\mathrm{a}}$ & $0.37 \pm 0.12^{\mathrm{a}}$ & $0.13 \pm 0.01^{b}$ & $0.15 \pm 0.02^{b}$ & $0.14 \pm 0.02^{b}$ & $0.18 \pm 0.03^{b}$ \\
\hline Palmitoleic $\mathrm{C}_{16: 1}$ & $3.40 \pm 0.10^{\mathrm{a}}$ & $3.40 \pm 0.10^{\mathrm{a}}$ & $2.64 \pm 0.24^{\mathrm{b}}$ & $2.34 \pm 0.15^{\mathrm{b}}$ & $2.18 \pm 0.22^{b}$ & $2.38 \pm 0.16^{\mathrm{b}}$ \\
\hline Heptadecenoic $\mathrm{C}_{17: 1}$ & $0.36 \pm 0.05^{\mathrm{a}}$ & $0.39 \pm 0.06^{\mathrm{a}}$ & $0.19 \pm 0.03^{b}$ & $0.19 \pm 0.03^{b}$ & $0.21 \pm 0.02^{\mathrm{b}}$ & $0.22 \pm 0.03^{b}$ \\
\hline Oleic $\mathrm{C}_{18: 1}$ & $25.91 \pm 1.18^{\mathrm{a}}$ & $23.69 \pm 1.04^{\mathrm{a}}$ & $49.03 \pm 3.31^{\mathrm{b}}$ & $48.26 \pm 3.00^{\mathrm{b}}$ & $50.46 \pm .2 .45^{\mathrm{b}}$ & $46.78 \pm 2.23^{\mathfrak{l}}$ \\
\hline \multicolumn{7}{|l|}{ Essential fatty acids } \\
\hline Linoleic $\mathrm{C}_{18: 2}$ & $5.93 \pm 0.80^{\mathrm{a}}$ & $6.17 \pm 0.50^{\mathrm{a}}$ & $9.63 \pm 2.01^{b}$ & $11.80 \pm 3.88^{b}$ & $8.99 \pm 1.37^{b}$ & $7.32 \pm 0.60^{\mathrm{b}}$ \\
\hline
\end{tabular}

F control sample (fresh cheese); FA control sample (fresh cheese) with added antioxidant (dill extract); E fresh cheese with directly added olive oil; EA fresh cheese with directly added olive oil and antioxidant (dill extract); C fresh cheese with encapsulated olive oil; CA fresh cheese with encapsulated olive oil and antioxidant (dill extract).

values of fat on the first and on the last day of storage at $4 \pm 1^{\circ} \mathrm{C}$ for seven days (Figure 2). The higher degree of oxidation established in samples $\mathrm{E}$ and EA compared to variants $\mathrm{C}$ and $\mathrm{CA}$ was due to the fact that oil encapsulation restricted the contact of oil with oxygen, restricting the oxidation process. The resulting data

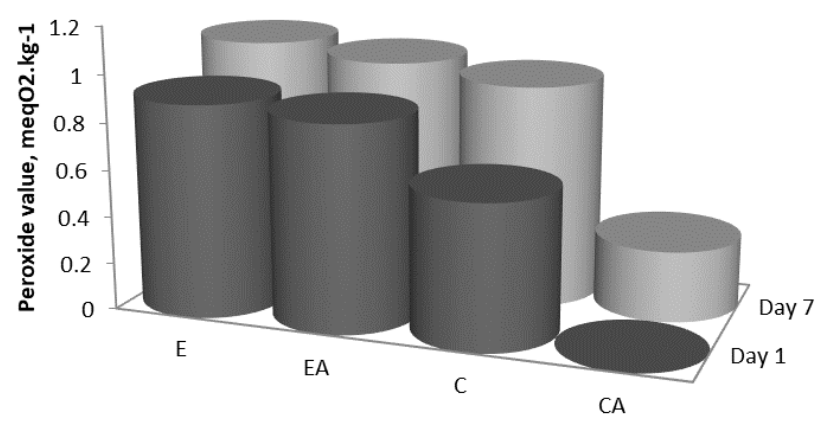

Figure 2. Peroxide value changes in different fresh cheese samples at 1st and 7th day of storage. E: fresh cheese with directly added olive oil, EA: fresh cheese with directly added olive oil and antioxidant (dill extract), C: fresh cheese with encapsulated olive oil, CA: fresh cheese with encapsulated olive oil and antioxidant (dill extract).

correspond to the results obtained by other researches (Tamjidi et al., 2012).

Variants E and EA were characterized by relatively higher peroxide values, which were probably due to the higher content of unsaturated fatty acids, which are particularly sensitive to oxidation. This was described by Farbod et al. (2013) who reported that peroxide value and thiobarbituric acid (TBA) value of feta cheese fortified with olive oil and fish oil increased during the ripening period of 60 days at $5^{\circ} \mathrm{C}$.

\subsection{Microbiological analysis}

Lactococcus counts may vary according to the

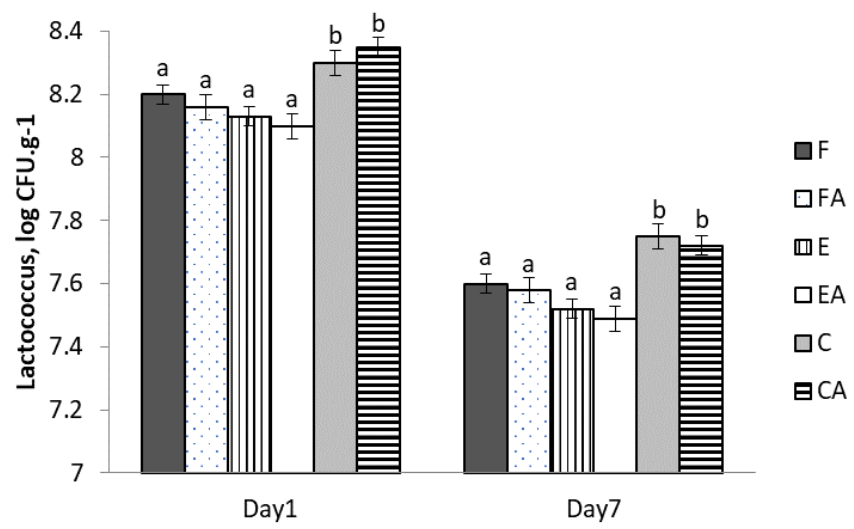

Figure 3. Changes in total count of Lactococcus in different fresh cheese samples at 1st and 7th day of storage. F: control sample (fresh cheese), FA: control sample (fresh cheese) with added antioxidant (dill extract), E: fresh cheese with directly added olive oil, EA: fresh cheese with directly added olive oil and antioxidant (dill extract), $\mathrm{C}$ : fresh cheese with encapsulated olive oil, CA: fresh cheese with encapsulated olive oil and antioxidant (dill extract). Different letters between days show statistically significant differences $(\mathrm{P}<$ 0.05 ) during storage. 
different conditions (Fajardo et al., 2016). The growth of mesophilic lactic acid bacteria in the experimental cheese variants during the studied period of storage was traced by the change in the total Lactococcus count. Higher content of lactic acid bacteria in samples $\mathrm{C}$ and CA on the first day of storage was established, compared to other samples (Figure 3).

The more intensive microbiological and biochemical processes of lactose fermentation in samples F, FA, E and EA correlated with the established higher levels of titratable acidity and $\mathrm{pH}$ (Figure $1 \mathrm{~A}$ and $\mathrm{B}$ ). The extended exponential phase of the growth of Lactococcus in samples $\mathrm{C}$ and $\mathrm{CA}$ was explained by the moderate rate of acid formation in cheese (Figure $1 \mathrm{~A}$ and B). Lower storage temperatures were unfavourable for the growth of lactic acid bacteria and the Lactococcus count. Similar data were obtained by Ammar et al. (1999).

\subsection{Sensory evaluation}

The sensory characteristics of cheeses were significantly improved with the encapsulation of olive oil. The results of the sensory analysis were shown (Figure 4).

The data obtained showed that the samples of fresh cheese F, FA, C and CA were characterized by higher sensory evaluation scores in comparison with variants $\mathrm{E}$ and EA. This result may be due to the higher peroxide value in these samples (Figure 2 and 4). This tendency was observed by other authors (Felfoul et al., 2015).

\section{Conclusion}

The comparative study on the possibility to use olive oil - directly in the form of an emulsion, or encapsulated, showed that the addition of encapsulated oils and a natural antioxidant increased the oxidative stability of the unsaturated fatty acids. The resulting fresh cheese was characterized by a higher content of unsaturated fatty acids as compared with the product obtained from milk, which has proven health effects in the prevention of various diseases in humans. Moreover, the sensory evaluation scores of cheese with encapsulated olive oil and dill extract were the highest.

\section{Conflict of interest}

The authors declare no conflict of interest.

\section{Acknowledgments}

We acknowledge Magalie Poirieux for her enthusiastic work during this research.

\section{References}

Abdelhamid, A., Martin, N., Bridges, C., Brainard, J., Wang, X., Brown, T., Hanson, S., Jimoh, O., Ajabnoor, S., Deane, H., Song, F. and Hooper, L. (2018). Polyunsaturated fatty acids for prevention and treatment of diseases of the heart and circulation.

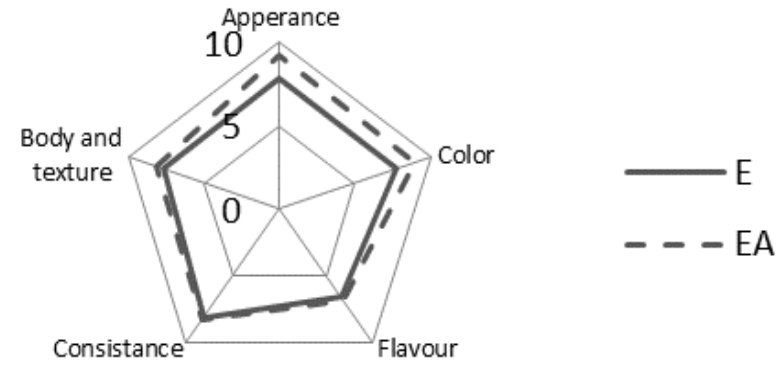

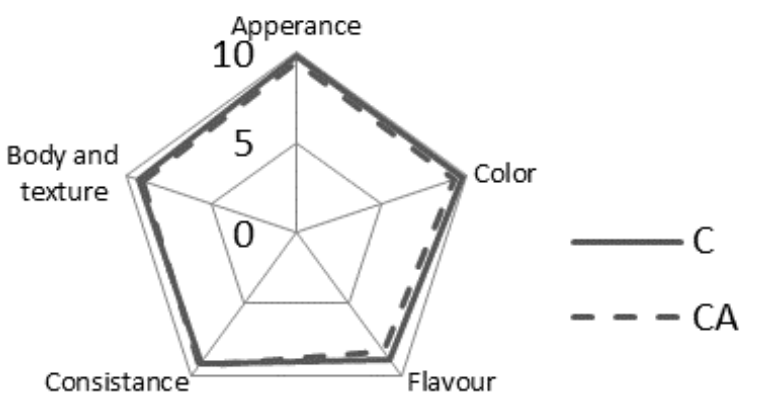

Figure 4. Sensory profile of different cheese samples after 7 days of storage. F: control sample (fresh cheese), FA: control sample (fresh cheese) with added antioxidant (dill extract), E: fresh cheese with directly added olive oil, EA: fresh cheese with directly added olive oil and antioxidant (dill extract), C: fresh cheese with encapsulated olive oil, CA: fresh cheese with encapsulated olive oil and antioxidant (dill extract). 
Cochrane Database of Systematic Reviews, 11 (CD012345). doi.org/10.1002/14651858.CD012345.pub3

https://

Aini, N., Sustriawan, B., Prihananto, V., Sumarmono, J., Ramadan, R. and Romadhon, D. (2020). Formulation of low-fat cheese analogue from sweet corn extract using papain and lime extract as coagulant. Food Research, 4(4), 1071-1081. https://doi.org/10.26656/ fr.2017.4(4).395

Al-Ismail, K, Al-Hiary, B. and Al-Dabbas, M. (2015). Evaluation of Some Chemical and Sensory Properties of Processed Cheese Analogue with Selected Vegetable Oils. International Journal of Chemical and Process Engineering Research, 2(6), 75-85. https://doi.org/10.18488/ journal.65/2015.2.6/65.6.75.85

Amit, S., Uddin, M., Rahman, R., Islam, S. and Khan, M. (2017). A review on mechanisms and commercial aspects of food preservation and processing. Agriculture and Food Security, 6(51), 1-22. https:// doi.org/10.1186/s40066-017-0130-8

Ammar, M., EL-Shazly, A., Nasr, M. and Omar, I. (1999). Comparative study on recombined Labneh, with buffalo and cow milk Laneh. I. Effect of level on consumer acceptability. Egyptian Journal of Dairy Science, 27, 127-139.

Bakry, A., Abbas, S., Ali, B., Majeed, H., Abouelwafa, M., Mousa, A. and Liang, L. (2016). Microencapsulation of oils: a comprehensive review of benefits, techniques, and applications. Comprehensive Reviews in Food Science and Food Safety, 15(1), 143-182. https://doi.org/10.1111/15414337.12179

Bligh, E. and Dyer, W. (1959). A rapid method for total lipid extraction and purification. Canadian Journal of Biochemistry and Physiology, 37, 911-917. https:// doi.org/10.1139/059-099

Bulgarian National Standard (BNS) 1111-80. (1980). Milk and milk products. Determination of acidity. Bulgaria

Bulgarian National Standard (BNS) 15612-83. (1983). Milk and milk products. Sensory analysis. Bulgaria

Chang, C. and Nickerson, M. (2018). Encapsulation of omega 3-6-9 fatty acids-rich oils using protein-based emulsions with spray drying. Journal of food science and technology, 55(8), 2850-2861. https:// doi.org/10.1007/s13197-018-3257-0

Dal Bello, B., Torri, L., Piochi, M., Bertolino, M. and Zeppa, G. (2017). Fresh cheese as a vehicle for polyunsaturated fatty acids integration: effect on physico-chemical, microbiological and sensory characteristics. International Journal of Food
Sciences and Nutrition, 68(7), 800-810. https:// doi.org/10.1080/09637486.2017.1301891

Dawczynski, C., Martin, L., Wagner, A. and Jahreis, G. (2010). n-3 LC-PUFA-enriched dairy products are able to reduce cardiovascular risk factors: a doubleblind, cross-over study. Clinical Nutrition, 29(5), 592-599. https://doi.org/10.1016/j.clnu.2010.02.008

Domínguez, R., Pateiro, M., Gagaoua, M., Barba, F., Zhang, W. and Lorenzo, J. (2019). A Comprehensive Review on Lipid Oxidation in Meat and Meat Products. Antioxidants, 8(10), 429. https:// doi.org/10.3390/antiox8100429

Eustone, S. (2008). Emulsifiers in Dairy Products and Dairy Substitutes. In Hasenhuettl, G. and Hartel, R. (Eds). Food emulsifiers and their applications. $2^{\text {nd }}$ ed., p. 195-233. Berlin: Springer. https:// doi.org/10.1007/978-0-387-75284-6 7

Fajardo, J., Ossa, T. and Elvis-Hernández, R. (2016). Effect of pasteurization and starter cultures on physicochemical and microbiological properties of costeño cheese. Revista Facultad Nacional de Agronomía Medellín, 69(2), 8007-8014. http:// dx.doi.org/10.15446/rfna.v69n2.59145

Farbod, F., Kalbasi, A., Moini, S., Emam-Djomeh, Z., Razavi, H., Mortazavi, A. and Beheshti, H. (2013). The Effects of Storage Time on Physiochemical, Rheological, MicroStructural and Sensory Properties of Feta Cheese Fortified with Fish and Olive Oils. Journal of Nutrition and Food Sciences, 3(5), $1000230 . \quad$ https://doi.org/10.4172/21559600.1000230

Felfoul, I., Bornaz, S., Baccouche, A., Sahli, A. and Attia, H. (2015). Low-fat Gouda cheese made from bovine milk-olive oil emulsion: physicochemical and sensory attributes. Journal of Food Science and Technology, 52(10), 6749-6755. https:// doi.org/10.1007/s13197-015-1736-0

Felfoul, I., Sahli, A., Samet-Bali, O., Attia, H. and Bornaz, S. (2016). Comparative study of white brined cheeses obtained from whole milk and milkolive oil emulsion: Physicochemical and sensory properties. Mljekarstvo, 66(4), 304-311. https:// doi.org/10.15567/mljekarstvo.2016.0406

ISO. (2004). Determination of fat content in cream cheese - Gravimetry, (Schmid-BondzynskiRatzlaff). ISO 1735|IDF 5:2004. Switzerland.

Isbilir, S. and Sagiroglu, A. (2011). Antioxidant Potential of Different Dill (AnethumGraveolens L.) Leaf Extracts. International Journal of Food Properties, 14(4), 894-902. https:// doi.org/10.1080/10942910903474401

ISO. (2006). Milk, milk products and mesophilic starter 
cultures - Enumeration of citrate-fermenting lactic acid bacteria - Colony-count technique at 25 degrees. ISO 17792:2006. Switzerland.

ISO. (2004). Animal and vegetable fats and oils Analysis by gas chromatography of methyl esters of fatty acids. ISO 5508:2004. Switzerland.

ISO. (2000). Animal and vegetable fats and oils Preparation of methyl esters of fatty acids. ISO 5509:2000. Switzerland.

ISO. (1983). Analyse Sensorielle Methodologie. ISO 6654-83. Switzerland.

ISO. (2020). Microbiology of the food chain Preparation of test samples, initial suspension and decimal dilutions for microbiological examination Part 5: Specific rules for the preparation of milk and milk products. ISO 6887-5:2020. Switzerland.

ISO. (2008). Animal and vegetable fats and oils. Determination of peroxide value. Iodometric (visual) end point determination. ISO EN 3960:2008. Switzerland

Ivanova, M. (2016). Influence de la température de pasteurisation et de la quantité de présure sur le processus de coagulation mixte des émulsions laithuile. In Obtention de fromage à la composition régulée de la matière grasse, p. 29-30. Saarbrucken, Germany: Editions universitaires européennes.

Kaptan, B. and Sivri, G. (2018). Utilization of medicinal and aromatic plants in dairy products. Journal of Advancements in Plant Science, 1(2), 1-5.

Kyeong, K., Nam, M. and Bae, H. (2017). Characteristics of Gouda Cheese Supplemented with Chili Pepper Extract Microcapsules. Food Science of Animal Resources, 37(6), 833-839. https:// doi.org/10.5851/kosfa.2017.37.6.833

Lanier, J. and Corl, B. (2015). Challenges in enriching milk fat with polyunsaturated fatty acids. Journal of Animal Science and Biotechnology, 6(1), 26. https:// doi.org/10.1186/s40104-015-0025-0

Liu, A., Ford, N., Hu, F., Zelman, K., Mozaffarian, D. and Kris-Etherton, P. (2017). A healthy approach to dietary fats: understanding the science and taking action to reduce consumer confusion. Nutrition Journal, 16(1), 53. https://doi.org/10.1186/s12937017-0271-4

Nenov, N., Atanasova, T., Stoilova, I., Gochev, V., Girova, T. and Stoyanova, A. (2013). Low temperature extraction of essential oil bearing plants by liquefied gases. 11. Dill (Anethum graveolens L.). Scientific works "Food science, engineering and technologies - 2013"18-19 October 2013

Poirieux, M., Kostov, G., Denkova, R., Shopska, V., Ivanova, M., Balabanova, T. and Vlaseva, R. (2017).
Preparing capsules with a high oil content with application in milk industry. Acta Universitatis Cibiniensis, Series E: Food technology, 21(1), 1121. https://doi.org/10.1515/aucft-2017-0002

Ramji, D. (2019). Polyunsaturated Fatty Acids and Atherosclerosis: Insights from Pre-Clinical Studies. European Journal of Lipid Science and Technology, 121(1), $\quad 1800029 . \quad$ https://doi.org/10.1002/ ejlt.201800029

Ruiz, J., Ortiz, E. and Segura, M. (2017). Encapsulation of vegetable oils as source of omega-3 fatty acids for enriched functional foods. Critical Reviews in Food Science and Nutrition, 57(7), 1423-1434. https:// doi.org/10.1080/10408398.2014.1002906

Siri-Tarino, P., Chiu, S., Bergeron, N. and Krauss, R. (2015). Saturated Fats Versus Polyunsaturated Fats Versus Carbohydrates for Cardiovascular Disease Prevention and Treatment. Annual Review of Nutrition, 35, 517-543. https://doi.org/10.1146/ annurev-nutr-071714-034449

Tamjidi, F., Nasirpour, A. and Shahedi, M. (2012). Physicochemical and sensory properties of yogurt enriched with microencapsulated fish oil. International Journal of Food Science and Technology, 18(4), 381-390. https:// doi.org/10.1177/1082013211428212

Vlaseva, R., Ivanova, M., Petkova, N., Denev, P., Stoyanova, A. and Schreiner, M. (2014). Obtaining stable food emulsions between milk and corn oil. Bulgarian Journal of Agricultural Science, 20(5), 1085-1089.

Xu, D., Li, Y., Meng, X., Zhou, T., Zhou, Y., Zheng, J., Zhang, J. and Li, H. (2017). Natural Antioxidants in Foods and Medicinal Plants: Extraction, Assessment and Resources. International Journal of Molecular Sciences, 18(1), 10096. https://doi.org/10.3390/ ijms 18010096 